\title{
Mediation of Academic Self-esteem on Relationship between Grades and Psychological Disengagement
}

Habil Otanga

Lecturer, Department of Psychology, University of Nairobi, Kenya.

Type of Work: Peer-Reviewed

DOl: http://dx.doi.org/10.21013/jems.v15.n4.p2

\section{How to cite this paper:}

Otanga, H. (2019). Mediation of Academic Self-esteem on Relationship between Grades and Psychological Disengagement. IRA International Journal of Education and Multidisciplinary Studies (ISSN 2455-2526), 15(4), 115-121.doi: http://dx.doi.org/10.21013/jems.v15.n4.p2

(C) Institute of Research Advances.

This work is licensed under a Creative Commons Attribution-Non Commercial 4.0 International License subject to a proper citation to the publication source of the work.

Disclaimer: The scholarly papers as reviewed and published by the Institute of Research Advances (IRA) are the views and opinions of their respective authors and are not the views or opinions of the IRA. The IRA disclaims of any harm or loss caused due to the published content to any party.

Institute of Research Advances is an institutional publisher member of Publishers International Linking Association Inc. (PILA-CrossRef), USA. The institute is an institutional signatory to the Budapest Open Access Initiative, Hungary advocating the open-access of scientific and scholarly knowledge. The Institute is a registered content provider under Open Access Initiative Protocol for Metadata Harvesting (OAI-PMH).

The journal is indexed \& included in WorldCat Discovery Service (USA), CrossRef Metadata Search (USA), WorldCat (USA), OCLC (USA), Open J-Gate (India), EZB (Germany) Scilit (Switzerland), Airiti (China), Bielefeld Academic Search Engine (BASE) of Bielefeld University, Germany, PKP Index of Simon Fraser University, Canada. 


\begin{abstract}
The motivational basis for students' school outcomes remains an area of great concern. The purpose of the present study was to investigate whether academic self-esteem mediates the influence of grades on psychological disengagement. Data for 453 secondary school students whose age ranged from 15-19 years $\left(M_{\text {age }}=17.20, S D=1.09\right.$; $53.6 \%$ females) were collected using a questionnaire and analyzed using SPSS. Findings show significantly higher discounting than discounting, and no significant differences in discounting and devaluing between the highest and lowest achievers. Academic selfesteem significantly mediated the influence of grades on discounting and devaluing. Practical implications of findings in school contexts are discussed.
\end{abstract}

Keywords: Academic self-esteem, devaluing, discounting, grades, psychological disengagement

\title{
Introduction
}

Psychological disengagement is a self-protective strategy against negative outcomes in value-relevant domains. While psychological disengagement may help to maintain or boost self-image despite threatening feedback [1, 2, 3], it has implications for achievement motivation and subsequent performance. Psychologically disengaged students are more likely to view school as a nuisance, reduce the effort in academic activities and become indifferent to academic pursuit with implications for achievement and school dropout [4]. While researchers agree that the two facets of psychological disengagement - discounting and devaluing are negatively related to academic achievement, few studies support this assertion in the context of repeated failure. It is therefore important to understand the motivational reasons that underlie prevailing lack of interest in school and subsequent dropout rates cited among the adolescent population.

The current study was conducted in the academic domain among a nationally representative sample of high school students in Mombasa, Kenya. The school context is important because it is easy to measure academic ability against objective criteria of grades, and the school context also provides a realistic environment to study changes in selfevaluation due to feedback. Academic achievement is important because it determines students' significant life outcomes, for instance, higher education and career opportunities; in addition to having implications for self-worth. Hence failure in academics should reduce esteem while success should boost it. Students will consequently adopt self-protective mechanisms when their esteem is threatened by feedback in the academic domain.

\section{Achievement, self-esteem and psychological disengagement}

Success in the academic domain is an important source of self-worth and failure is indicative of incompetence and loss of worth [5, 6]. Academic failure is devastating and the extent to which it can affect self-esteem, and psychological disengagement from the academic domain through its linkage to self-worth evaluation is the subject of previous research[7, 8, 9]. Though not all individuals behave the same way when faced with failure, the selfworth theory [5] and relevant literature show that the relationship between poor achievement and psychological disengagement depend on the extent to which the specific domain is important in one's self-evaluation. Accordingly, the strength of the association fluctuates as a function of perceived successes or setbacks in domains on which selfesteem is contingent [9].

In school, it is expected that students' sense of self-worth is anchored on successes and failures in the academic domain. Evidence abounds that academics is actually important for students' self-evaluation in school [7, 8, 10] and overall self-worth evaluation [6,11]. Crocker et al's[7] study provided evidence that increases and decreases in daily global self-esteem in response to successes and failures depend on a person's contingencies of self-worth. Because individuals aspire to feel worthy, domains on which self-worth is staked have motivational implications. When a student discounts or devalues, academic self-esteem is disconnected from overall feelings of self-esteem. Students' sense of self-worth can be threatened by poor scores in tests. This creates a need to self-protect [2, 3, 12, 13]. Experimental manipulation [7] provides evidence of a negative relationship between exposure to failure and confidence and a positive relationship between grades and misidentification for students highly identified with academics. This is in line with Bandura's self-efficacy theory which suggests that positive feedback increases individuals' sense of self-efficacy while failure and negative feedback weakens it [14]. Academically contingent students will, therefore, be affected more by failure which indicates to them that they are worthless and are more 
likely to use strategies that reduce the impact of the bad grades, for instance, discounting feedback in the domain [1, $8,9]$.

Consequently, individuals will avoid the decrease in self-esteem that failure may bring in domains in which they have invested their self-worth. When a student attempts to satisfy a contingency of self-worth through being competent by getting good grades in school but fails in the attempt, self-protective mechanisms are put in place. On the one hand, the effort may be increased on future tasks, or, on the other hand, may be withdrawn altogether [14]. Academic self-esteem is therefore positively related to motivation with higher academic self-esteem corresponding to higher motivation in a subsequent task. However, research shows that disengaging from negative feedback helps stigmatized students to maintain self-worth, feelings of competence and motivation in the academic domain by not internalizing the unfavourable feedback[1, 15]. Discounting could therefore positively correlate with persistence.

Research shows a positive relationship between educational performance and academic self-esteem[2, 6, 21]. Findings suggest that students whose self-worth is contingent on academics will delink self-esteem from the academic domain when faced with poor performance in tests. Such students are likely to seek self-protective strategies including discounting and devaluing. Students will, therefore, be motivated to get good grades that will verify their valued self-images. Steele [17] suggests that a decrease in academic self-esteem due to poor grades is likely to weaken the students' self-worth which necessitates self-protection. Hence it is hypothesized that academic self-esteem mediates the relationship between grades and discounting and devaluing. Under conditions of poor performance in the academic domain, the relationship between academic self-esteem and global self-worth is affected. In turn, one is likely to misidentify to maintain worth in the face of such failure. It, therefore, leads to the suggestion that it is not failure that causes misidentification, but the drop in academic self-esteem that follows[6].

Whereas the bulk of literature links poor performance and discounting through academic self-esteem, some literature indicates that high performing students may also discount the validity of tests [2]. This perspective suggests that high performing students' academic self-esteem can only be maintained by psychological disengagement, especially discounting. These are the students in the school who perform higher than external evaluation can provide positive feedback. Discounting, unlike devaluing, therefore buffers self-evaluation without decreasing achievement motivation [18] but is counterproductive for students who do not need to self-protect. Devaluing is not helpful even for individuals with low self-esteem because the academic domain is highly valued in society.

Research on the extent to which academic self-esteem mediates the influence of academic achievement on psychological disengagement support the hypothesis that failure only leads to disengagement when students' selfevaluation in the academic domain is affected by the reduction in self-esteem that follows [6, 13, 15, 16].Cumulatively, these findings point at the central role of self-esteem in academic achievement and that of failure feedback in individuals' self-evaluation. What remains to be done in line with these findings is to examine whether lowered self-evaluation leads to discounting and devaluing in the context of repeated school failure. This study, therefore, hypothesised that academic achievement would positively correlate with academic self-esteem; and academic self-esteem would in turn negatively correlate with discounting and devaluing.

While a considerable body of research from the USA and Europe exists, the nature of samples exposed to negative stereotypes of intellectual inferiority, bias, stigma and ethnic prejudice [13,16,18, 19]suggest that discounting and devaluing are group responses. Other findings using highly selective samples, for instance, students from elite universities with high levels of academic self-esteem [20]diminish the generalizability of such findings to majority populations. Secondly, findings of experimental studies[7, 16] have limited external validity and focus on short-term shifts in self-esteem in relation to psychological disengagement.

In summary, the research literature does not consistently support the question concerning the negative or positive consequences that follow the reduction in self-esteem attached to the academic domain. It appears that under some circumstances, psychological disengagement in the short-term is adaptive and positive. Additionally, the extent to which shifts in academic self-esteem due to failure feedback play an adaptive role remains debatable. To understand the motivational mechanisms underlying psychological disengagement, further research is needed among more inclusive populations. The current study sought to fill this lacuna by using a sample from a nationally-representative population of secondary school students in Kenya. 


\section{Method}

\section{Participants}

Participants were 453 third level students $\left(M_{a g e}=17.20, S D=1.09 ; 53.6 \%\right.$ female $)$ attending 12 urban public and private secondary schools in Mombasa, Kenya's second-largest city. The public schools' category consists of county and national schools; the latter who solely admit high performing students from across the country. County schools admit students from their respective regions following the new government policy on mass transition from primary to secondary school. Therefore, all students who sit end of primary school examinations find placement in county schools across the country with little regard to final primary school grades. The random sample selected was therefore expected to be nationally representative, cutting across ethnic, achievement and social status groups. This is one originality of the current study.

All participants provided written consent before participation. They were informed that researchers were interested in understanding what made students sustain interest in academics. Research approval was provided by the National Commission for Science, Technology and Innovation (NACOSTI) and the study carried out during regular class hours under the supervision of class teachers and the researcher.

\section{Measures}

Participants were presented with a questionnaire containing items on academic self-esteem and psychological disengagement and demographics.

\section{Academic achievement}

Grades were taken from school records for all eight subjects (three compulsory - English, Kiswahili, Mathematics; one of two science subjects - Biology and Physics in addition to Chemistry that is compulsory; and three subjects from arts and technical areas - History, Geography, Religious Education, Business Education, French, Arabic, Home science and Technical drawing). The cumulative mean grade after three school terms were computed as a percentage. In the Kenyan education system, a grade higher than 70 is considered excellent while a grade below 35 is a fail.

\section{Academic self-esteem}

Academic self-esteem was measured using the 7-item Performance Self-esteem subscale of the State Self-esteem scale [21]on a 5-point Likert scale ( $1=$ strongly disagree and $5=$ strongly agree). Sample items include: 'I feel confident about my abilities'; 'I feel frustrated about my academic performance' (reverse coded); and 'I feel smart as others'. All negatively worded items were reverse coded so that high scores indicated higher academic selfesteem. A reliability index of 0.71 was computed for the measure.

\section{Psychological disengagement}

The Intellectual Engagement Inventory [2] was used to measure psychological disengagement on a 5-point Likert scale $(1=$ strongly disagree and $5=$ strongly agree). Discounting was measured using four items: 'I feel that school examinations are fair tests of my abilities (reverse coded); 'In general, I feel that school examinations are a good measure of my intelligence' (reverse coded); Most examinations do not really measure what they are supposed to'; and 'I feel that school examinations are definitely biased against me'. Higher means indicated higher discounting. A reliability index of 0.67 was found. Four items assessed devaluing: 'Being good at academics is an important part of whom I am' (reverse coded); 'I always feel good about myself when I do well on an academic test' (reverse coded); 'Academic success is not very valuable to me'; and 'It usually doesn't matter to me how I do in school'. Higher means indicated higher devaluing. Reliability analysis yielded an index of 0.68.

\section{Results}

Four questionnaires were incomplete and were excluded from data analysis. The final sample for analysis consisted of 449 students $\left(\mathrm{M}_{\mathrm{age}}=17.20, \mathrm{SD}=1.09 ; 54.1 \%\right.$ female $)$. Means, standard deviations and correlations for all variables were calculated. Table 1 shows significant and positive correlations between discounting and devaluing; significant and positive correlations between academic achievement and academic self-esteem; and significant and negative correlations between academic self-esteem and both discounting and devaluing. 
IRA-International Journal of Education $छ$ Multidisciplinary Studies

Table 1. Descriptive analysis of variables

\begin{tabular}{lllllll}
\hline Variables & Mean & SD & Grades & ASE & Discounting & Devaluing \\
\hline Grades & 49.41 & 9.97 & 1 & & & \\
ASE & 21.79 & 5.06 & $.27^{* *}$ & 1 & & \\
Discounting & 5.36 & 2.13 & -.07 & $-.16^{* *}$ & 1 & 1 \\
Devaluing & 8.81 & 3.01 & $-.19^{* *}$ & $-.17^{* *}$ & $.25^{* *}$ & 1 \\
\hline
\end{tabular}

Note: $* * p<.001$

Independent t-tests and one-way ANOVA were calculated to examine gender and age differences respectively in grades, academic self-esteem and discounting and devaluing. Significant gender differences were found in grades, $t(447)=-2.81, p=.005$, with higher grades among female $(M=50.62, S D=10.30)$ than male students $(M=47.98$, $S D=9.46$ ). Significant gender differences were also found in devaluing, $t(447)=2.90, p=.004$, with higher reports among male students. No significant gender differences were found in academic self-esteem and discounting. No age differences were found for any of the variables measured. As predicted, significant differences were found between discounting and devaluing, $t(448)=22.67, p<.001$, with higher discounting $(M=8.81, S D=3.01)$ than devaluing $(M=5.36, S D=2.13)$ reported.

\section{Regression analysis}

Two separate regression analyses were conducted to test the contribution of grades on discounting and devaluing. Grades significantly predicted devaluing, $F(1,447)=17.29, p<.001$, but not discounting, $F(1,447)=1.97, p=.161$. In both cases, a negative relationship was found. The sample was then categorized into low and high achievers on the basis of mean scores over three school terms. Students who scored a mean grade of 70 and above; and 34 and below were classified as high and low achievers respectively. T-test analysis on the sample found no significant differences in discounting, $t(37)=.39, p<.699$, between low $(M=8.70, S D=3.74)$ and high achievers $(M=8.32$, $S D=2.16)$. No significant differences were also found in devaluing, $t(37)=1.36, p<.183$, between low $(M=5.90$, $S D=2.27)$ and high achievers $(M=5.05, S D=1.54)$.

\section{Mediation analysis}

To test whether academic self-esteem mediated the influence of grades on disengagement the SPSS PROCESS Macro [22] was used. To assess the indirect effect, a bootstrap procedure of 5000 samples and a bias-corrected 95\% confidence interval (CI) was used. Significant indirect effects were reported if the confidence intervals were entirely above zero. Unstandardized coefficients are reported.

Grades were significantly and negatively associated with discounting, $F(2,447)=5.87, p=.003, R^{2}=.03$, and devaluing, $F(2,446)=9.82, p<.001, R^{2}=.04$, when academic self-esteem was included in the model. Higher grades predicted an increase in academic self-esteem which in turn predicted decrease in discounting and devaluing. The bootstrap 95\% bias-corrected confidence intervals for the indirect path between grades and discounting was significant $(\mathrm{B}=-.21$, CI $[-.372,-.066]$; similar to the path with devaluing $(\mathrm{B}=-.13$, CI $[-.257,-.039]$ which did not contain zero. Unstandardized coefficients are presented in Table 2.

Table 2. Direct and indirect effects of performance attributions on discounting and devaluing

\begin{tabular}{lllllll} 
Predictor & \multicolumn{2}{c}{ Discounting } & \multicolumn{3}{c}{ Devaluing } \\
\hline Grades & $\begin{array}{l}\text { Direct } \\
\text { effect }\end{array}$ & Indirect effect[95\%CI] & $\begin{array}{l}\text { Total } \\
\text { effect }\end{array}$ & $\begin{array}{l}\text { Direct } \\
\text { effect }\end{array}$ & $\begin{array}{l}\text { Indirect } \\
\text { effect[95\%CI] }\end{array}$ & $\begin{array}{l}\text { Total } \\
\text { effect }\end{array}$ \\
\hline & -.13 & -.21 & -.33 & $-.45^{*}$ & -.13 \\
{$[-.257,-.039]$} & $-.58^{* *}$ \\
\hline
\end{tabular}

Note: $* p<.05 ; * * p<.001$

\section{Discussion}

One aim of the present study was to establish whether academic self-esteem mediates the relationship between grades and psychological disengagement from the academic domain. Findings were expected to extend previous research to secondary school students from Africa. Findings of significant mediation of academic self-esteem on both discounting and devaluing indicate that previous findings could be replicated to students from majority populations in Africa. 
As hypothesized, better grades predicted an increase in academic self-esteem which negatively predicted discounting and devaluing. This supports the idea that grades by themselves do not lead to psychological disengagement but work through the reduction in esteem that follows [13, 20]. While previous studies have found this path to be less obvious for devaluing, findings of this study provide evidence that repeated poor grades lead to both discounting feedback and devaluing the academic domain. However, by finding higher reports of discounting, the present study replicates previous findings indicating that students are more likely to discount grades than devalue the academic domain [3]. This is expected in societies that highly value academic achievement as a stepping stone to future opportunities in higher education and career placement [19].

It seems, as in previous research [11, 23, 24], that male students in this sample derive self-esteem and a sense of identity from non-academic activities. This can be explained in part due to cultural expectations that put significantly higher pressure to excel in men as compared to women. It is possible that in the face of repeated poor grades, male students easily devalue the academic domain to protect the self against heightened anxiety arising out of culturally-enforced standards of success. Being successful in another domain is one way of affirming the self.

One interesting finding of the study was the absence of any significant differences in discounting and devaluing between high and low achievers. This finding suggests that high and low achievers use self-protective mechanisms for varying reasons. Previous research has found high achievers to discount the validity of feedback as a way of sustaining motivation, especially in cases where external evaluation does not adequately sustain esteem. It is only by lowering esteem that they are able to sustain motivation on subsequent tasks. Low achievers discount the validity of feedback to deflect the loss in esteem accompanying failure. It, therefore, seems likely that average students gain more from increase in academic self-esteem following good grades.

This study has some limitations. Firstly, the sample size comprised of urban secondary school students from one city in Kenya and hence findings need to be generalized with caution. Secondly, it is difficult to completely eliminate the likelihood of bias in feedback in the form of end of term examinations results. Thirdly, the measures of psychological disengagement used have not been previously used in research in Africa. Finally, it is difficult to make causal interpretations because of the correlational nature of the study. Variables which are likely to vary over time were measured at one point in time. Future studies may employ longitudinal designs to best capture variations in measures used.

Despite the limitations, the current study sheds new light on the effect of grades on psychological disengagement. It provides empirical support to the question as to whether psychological disengagement is a minority group's reaction to bias, prejudice and discrimination. Findings of the study show that both discounting and devaluing occur as selfdefensive responses to lowered esteem in the academic domain among students from the majority population. The results can, therefore, be generalized to students in all ethnic groups because they involve variables and processes common to all students. Findings support the assumption that poor grades lead to psychological disengagement via decrease in academic self-esteem and thus provide a more holistic understanding of the link between academic achievement and psychological disengagement among secondary school students from the majority population.

The school system could benefit from these findings through the strategic use of the methods of giving performance feedback. Understanding the process underlying feedback has implications for learners' motivation, esteem and persistence. For instance, since objective performance feedback such as grades compares students against their peers, it fosters a sense of contingent self-worth, where the student's value is equated to how successful they are in academics. This is likely to create helpless reactions to subsequent tasks following previous repeated failure which will be attributed to internal and stable factors, especially ability [25].

Secondly, it is evident that male students in this study feel the stigma associated with school failure more than female students and hence devalue the academic domain to protect the self. Schools should aspire to de-emphasize academic excellence as a measure of worth in addition to providing models of success outside academics. Findings of this study may hence support the adoption of diverse feedback processes which aim to help students deal more positively with subsequent tasks. Future studies may examine cross-cultural differences in devaluing among male students. 


\section{References}

[1]. Crocker, J., Major, B., \& Steele, C. (1998). Social stigma. In D. T. Gilbert \& S. T. Fiske (Eds.), The handbook of social psychology (Vol. 2, 4th ed., pp. 504-553). Boston: McGraw-Hill.

[2]. Major, B., \&Schmader, T. (1998). Coping with stigma through psychological disengagement. In J. K. Swim \& C. Stangor (Eds.), Prejudice: The target's perspective (pp. 219-241). San Diego, CA: Academic Press.

[3]. Schmader, T., Major, B. \&Gramzow, R. H. (2001). Coping with ethnic stereotypes in the academic domain: Perceived injustice and psychological disengagement. Journal of Social Issues, 57(1), 93-111. http://doi.org/10.1111/00224537.0203

[4]. Trout, P. A. (1997). Disengaged students and the decline of academic standards. Academic Questions, 10(2), 46-56. http:dx.doi.org/10/1007/s12129-997-1067-3

[5]. Covington, M. V. (1984). The self-worth theory of achievement motivation: Findings and implications. The Elementary School Journal, 85(1), 4-20. http://dx.doi.org/10.1086/461388

[6]. Osborne, J. W. (1995). Academics, self-esteem and race: A look at the underlying assumptions of the disidentification hypothesis. Personality and Social Psychology Bulletin, 21, 449-455.

[7]. Crocker, J., Luhtanen, R. K., Cooper, M. L., Bouvrette, A. (2003). Contingencies of self-worth in college students: Theory and measurement. Personality Processes and Individual Differences, 85(5), 894-908. DOI: 10.1037/00223514.85.5.894

[8]. Crocker, J., Sommers, S. R., \&Luhtanen, R. K. (2002). Hopes dashed and dreams fulfilled: Contingencies of selfworth and graduate school admissions. Personality and Social Psychology Bulletin,28(9), 1275-1286. http://dx.doi.org/10.1177/10461672022812012

[9]. Crocker, J., \& Wolfe, C. T. (2001). Contingencies of self-worth. Psychological Review, 108(3), 593-693. DOI: 10.1037//0033-295X.108.3.593

[10]. Crocker, J., Karpinski, A., Quinn, D. M., \& Chase, S. K. (2003). When grades determine self-worth: Consequences of contingent self-worth for male and female engineering and psychology majors. Journal of Personality and Social Psychology, 85(3), 507-516. DOI: 10.1037/0022-3514.85.3.507

[11]. Osborne, J. W. (1997). Race and academic disidentification. Journal of Educational Psychology, 89, $728-735$.

[12]. Major, B., Spencer, S., Schmader, T., Wolfe, C., \& Crocker, J. (1998). Coping with negative stereotypes about intellectual performance: The role of psychological disengagement. Personality and Social Psychology Bulletin, 24, 34-50. DOI: $10.1177 / 0146167298241003$

[13]. Regner, I., \& Loose, F. (2006). Relationship of sociocultural factors and academic self-esteem to school grades and school disengagement in North African French adolescents. British Journal of Educational Psychology, 45, 777797. DOI: $10.1348 / 014466605 X 83610$

[14]. Fishbach, A., \& Finkelstein, S. R. (2012). How feedback influences persistence, disengagement, and change in goal pursuit, In H. Aarts\& A. Elliot (Eds.), Goal-directed behaviour (pp. 203-230).New York: Psychology Press.

[15]. Nussbaum, A. D., \& Steele, C. M. (2007). Situational disengagement and persistence in the face of adversity. Journal of Experimental Social Psychology, 43, 127-134. doi:10.1016/j.jesp.2005.12.007

[16]. Verkuyten, M., \& Thijs, J. (2004). Psychological disidentification with the academic domain among ethnic minority adolescents in The Netherlands. British Journal of Educational Psychology, 74, 109-125. DOI: $10.1348 / 000709904322848842$

[17]. Steele, C. M. (1997). A threat in the air: How stereotypes shape intellectual identity and performance. American Psychologist, 52(6), 613-629. http://dx.doi.org/10.003-066X.52.6.613

[18]. Loose, F., Regner, I., Morin, A. J. S., \& Dumas, F. (2012). Are academic discounting and devaluing double-edged swords? Their relations to global self-esteem, achievement goals, and performance among stigmatized students. Journal of Educational Psychology, 104(3), 713-725. DOI: 10.1037/a0027799

[19]. Crocker, J., \& Major, B. (1989). Social stigma and self-esteem: The self-protective properties of stigma. Psychological Review, 96(4), 608-630. http://dx.doi.org/10.1037/0033-295X.96.4.608

[20]. Strambler, M. J., \& Weinstein, R. S. (2010). Psychological disengagement in elementary school among ethnic minority students. Journal of Applied Developmental Psychology, 31, 155-165. DOI: 10.1016/j.appdev.2009.11.006

[21]. Heatherton, T. F., \&Polivy, J. (1991). Development and validation of a scale for measuring state self-esteem. Journal of Personality and Social Psychology, 60(6), 895-910. http://dx.doi.org/10.0022-3514.60.6.895

[22]. Hayes, A. (2018). Introduction to mediation, moderation, and conditional process analysis: A regression-based approach $2^{\text {nd }}$ Edition. New York: The Guilford Press.

[23]. Cokley, K. \& Moore, P. (2007). Moderating and mediating effects of gender and psychological disengagement on the academic achievement of African American college students. Journal of Black Psychology, 33(2), 169-187.

[24]. Ogbu, J. U. (1992). Understanding cultural diversity and learning. Educational Researcher, 21, 5-14. http://dx.doi.org/10.3102/0013189X021008005

[25]. Skipper, Y. \& Douglas, K. (2012). Is no praise good praise? Effects of positive feedback on children's and university students' responses to subsequent failures. British Journal of Educational Psychology, 82, 327-339. DOI:10.1111/j.2044-8279.2011.02028.x 